\title{
Corner Wrinkling of a Square Membrane due to Symmetric Mechanical Loads
}

\author{
Joseph R. Blandino* \\ Member AIAA \\ Assistant Professor \\ Integrated Science and Technology Program \\ James Madison University \\ MSC 4102 \\ Harrisonburg, VA 22807 \\ 540-568-2757 \\ blandijx@jmu.edu \\ John D. Johnston \\ Member AIAA \\ Aerospace Engineer \\ NASA Goddard Spaceflight Center \\ Greenbelt, MD 20771 \\ John.D.Johnston.1@gsfc.nasa.gov \\ and \\ Urmil K. Dharamsi \\ Undergraduate Research Assistant \\ Integrated Science and Technology Program \\ James Madison University \\ MSC 4102 \\ Harrisonburg, VA 22807 \\ dharamuk@jmu.edu
}

${ }^{*}$ To receive correspondence 


\title{
Corner Wrinkling of a Square Thin Film Membrane Due to Symmetric Mechanical Loads
}

\author{
$\underline{\text { Abstract }}$ \\ Thin-film membrane structures are under consideration for use in many future gossamer \\ spacecraft systems. Examples include sunshields for large aperture telescopes, solar sails, and \\ membrane optics. The development of capabilities for testing and analyzing pre-tensioned, thin- \\ film membrane structures is an important and challenging aspect of gossamer spacecraft \\ technology development. This paper presents results from experimental and computational \\ studies performed to characterize the wrinkling behavior of thin-film membranes under \\ mechanical loading. The test article is a $500 \mathrm{~mm}$ square membrane subjected to symmetric \\ corner loads. Data is presented for loads ranging from $0.49 \mathrm{~N}$ to $4.91 \mathrm{~N}$. The experimental \\ results show that as the load increases the number of wrinkles increases, while the wrinkle \\ amplitude decreases. The computational model uses a finite element implementation of Stein- \\ Hedgepeth membrane wrinkling theory to predict the behavior of the membrane. Comparisons \\ were made with experimental results for the wrinkle angle and wrinkled region. There was \\ reasonably good agreement between the measured wrinkle angle and the predicted directions of \\ the major principle stresses. The shape of the wrinkle region predicted by the finite element \\ model matches that observed in the experiments; however, the size of the predicted region is \\ smaller that that determined in the experiments.
}

\section{Introduction}

Very large, ultra-lightweight or 'gossamer' spacecraft are an enabling technology for many future space missions. Thin-film membrane structures (including sunshields, solar sails, inflatable antennas, and membrane optics) are a common element in these systems. Due to their 
unprecedented size and flexibility, gossamer spacecraft systems will require advanced modeling and testing technologies to support their development. The behavior of these structures can be highly nonlinear and challenging to model and test. Modeling and analysis techniques to predict nonlinear membrane behavior such as wrinkling should be validated through comparison with test results. However, ground testing of ultra-lightweight structures is inherently difficult due to the presence of gravity and the influence of instrumentation mass on structural behavior, and new test methods and non-contact instrumentation are needed. These needs are addressed in this manuscript through the study of analytical and experimental capabilities to predict the wrinkling behavior of a simple thin-film membrane structure.

\section{Previous Studies}

When a thin-film membrane is subjected to discrete tensile pre-loads localized buckling (or wrinkling) often results. This is because thin membranes have negligible bending stiffness and cannot resist compressive loads. The wrinkles serve to eliminate compressive stresses. ${ }^{1}$ The behavior of membrane structures has been studied previously by numerous researchers. A comprehensive overview of the modeling and analysis of membranes completed by Jenkins and. Leonard discusses many important contributions to this field of research. ${ }^{3}$ Finite element modeling techniques will be utilized extensively to predict the behavior of future thin-film membrane structures due to the nonlinear nature of the problem. Typically, the capabilities of commercially available finite element codes are inadequate to model all of the important aspects of membrane behavior. For example, modeling thin-film membrane structures using standard membrane elements is not advisable when the membranes experience significant wrinkling because the stress distribution in the membranes will not be represented properly. There are several approaches available for modeling membrane structures that account for the effects of 
wrinkles, including: the cable network method and modified membrane element methods. The cable network method was developed specifically for modeling the dynamics of pretensioned, wrinkled membranes. ${ }^{4}$ The approach is based on the established principle that load transfer in wrinkled regions takes place along wrinkle lines. The membrane is meshed with a network of cables (preloaded bar elements) that is mapped to the wrinkle pattern of the structure. This approach is useful for determining the out-of-plane structural dynamic characteristics of pretensioned, wrinkled membrane structures; however, it is limited in that it requires prior knowledge of the wrinkle pattern to create the cable network and does not account for in-plane shear or thermal effects. The cable network method has been previously used by one of the authors to model the Inflatable Sunshield In Space (ISIS) and one-tenth scale model Next Generation Space Telescope (NGST) sunshields. ${ }^{5}$ A more accurate representation of wrinkled membrane structural behavior can be obtained by using standard membrane finite elements in conjunction with a 'no-compression' membrane material model. ${ }^{6,7}$ These approaches start by developing a set of criteria by which the state of the membrane (wrinkled, slack, or taut) can be assessed. During the analysis, the material properties of each element are adjusted to account for the behavior associated with the particular state of that element. The advantages of these methods are that they can be used to: (1) accurately determine the state of stress in the membrane in the presence of wrinkling, (2) predict wrinkle characteristics including wrinkled region geometry and wrinkle directions, and (3) to model thermal-structural behavior.

Relatively few experimental studies concerning the behavior of pretensioned, thin-film membranes for space structures applications have been carried out over the years. During the 1980 's, a small amount of attention was given to membranes that would serve as reflector facets 
attached to stiff underlying structure, and reports by Sewall, Miserentino, and Pappa at NASA Langley Research Center $(\mathrm{LaRC})^{8}$ and Thomas and Veal at the Air Force Rocket Propulsion $\mathrm{Lab}^{9}$ are notable publications occurring in this era on the subject of thin-film tensioned membranes. The analysis and testing of inflatable structures (i.e. tubes and antennae) received considerable attention in the 1990's. Of particular relevance to this research are those studies involving pre-tensioned flat membrane structures (i.e. solar sails, sunshields, and optical membrane flats). Jenkins, ${ }^{10}$ Wong, ${ }^{11}$ and Kukathasan ${ }^{12}$ have published results in the past few years examining both the static and/or dynamic response of pre-tensioned thin-film membrane structures including experimental studies. Testing of membranes is inherently difficult not only because of the presence of gravity, but also because any instrumentation contacting the surface will alter membrane behavior. Two techniques have been employed successfully in the past to measure the surface of membrane structures. Jenkins et. al. ${ }^{10}$ used a capacitance based proximity sensor to measure the surface wrinkling of an isothermal membrane subjected to combined shear and tension loads. The sensor operated by measuring the change in capacitance between the sensor head and the membrane surface. This technique resolved out of plane wrinkle amplitudes as small as $+/-0.05 \mathrm{~mm}$. Pappa et. al. ${ }^{13}$ recently employed photogrammetry to determine the surface figure of a $5 \mathrm{~m}$ diameter inflatable space antenna. Photogrammetry is a technique that is commonly used by geographers and cartographers. It is the science of constructing a 3D contour map by triangulating common points from a series of $2 \mathrm{D}$ images. On a relatively large structure this technique had a precision on the out of plane displacements of between 0.9 and $2.8 \mathrm{~mm}$. These were obtained with a digital camera that had a resolution of $1792 \times 1200$ pixels. Both a capcitance sensor and photogrammetry were used by Blandino et. al. ${ }^{14}$ to study the behavior of a square membrane subjected to both mechanical and thermal loads. 
Although modeling of wrinkled membranes has occurred since the 1960's there has been very little comparison of these models with experimental results. This paper presents not only an experimental investigation into the wrinkling of a square Kapton membrane that is subjected to symmetric mechanical loads at the corners, but also a comparison of those results with those predicted by a computational model. The goal of the research is to quantify the wrinkle patterns near a membrane corner over a range of mechanical loads. The knowledge gained from this study will provide valuable insight into the phenomenon of membrane wrinkling. The data will also be useful for validating current modeling techniques.

\section{Experiment Design}

The design of the experiments is described in this section, including: the test specimen, test frame, load cases, and instrumentation.

\section{Test Specimen}

The test specimen used for this study was a 0.5 m (19.68 in) square Kapton HN membrane 2.54 x $10^{-2} \mathrm{~mm}(0.001 \mathrm{in})$ thick. The membrane has a $1 \times 10^{-3} \mathrm{~mm}\left(3.94 \times 10^{-5} \mathrm{in}\right)$ vapor deposited aluminum coating on one side. The test article was cut from a roll of material. The material was free of either significant material wrinkles or creases. The material was handled with cotton gloves and care was taken not to crease the membrane while mounting it in the test frame. The corners were reinforced with $0.12 \mathrm{~mm}(0.005 \mathrm{in})$ thick transparency film on both sides. The reinforcing was triangular in shape with dimensions of approximately $10 \mathrm{~mm} \times 10 \mathrm{~mm} \times 14.1$ mm (0.39 in. $\times 0.39$ in. $x 0.55$ in.). Mechanical loads were applied at discrete points at the corners of the membrane via Kevlar threads. Kevlar threads were also used to anchor the corners opposite the loads to the test frame. 


\section{Test Frame}

The membrane was oriented in the test frame and the axes taken as shown in Fig. 1. The frame was constructed from $25.4 \mathrm{~mm}$ (1.0 in.) 6061 aluminum square stock. The frame was $980 \mathrm{~mm} \mathrm{X}$ $980 \mathrm{~mm}$ (38.6 in. X 38.6 in.). The corners of the frame were reinforced with $6.35 \mathrm{~mm}(0.25 \mathrm{in}$.) aluminum plates. These aided in squaring the frame during assembly. Two legs were mounted to the frame at each of the bottom corners. Each leg met the frame at a $45^{\circ}$ angle. The legs were fabricated from aluminum stock identical to that used for the frame. The legs rested on vibration isolation pads. The thread attached to the top corner of the membrane was run through a 0.41 $\mathrm{mm}(0.016 \mathrm{in})$ diameter hole in a Delrin plug. The plug was attached to a mounting screw on the test frame. The thread on the left corner was attached to a mounting screw in an identical manner. The threads attached to the bottom and right sides were passed through $.46 \mathrm{~mm}(0.018$ in) diameter holes in Delrin plugs mounted to the test frame. Mechanical loads were applied by hanging masses from the ends of these threads. Once the membrane was loaded, the Kevlar threads were checked to ensure that they were square with the test frame. Excess thread at the top and right side were pulled taught and securely fastened to the test frame so that the membrane could not slip. During the squaring procedure and testing both axes were loaded symmetrically. Prior to hanging the manufacturer's value for each mass was verified using an electronic balance.

\section{$\underline{\text { Load Cases }}$}

A single membrane was used for a test series of four load cases. This allowed direct comparison between wrinkle patterns from case to case. The test sequence began with approximately a 0.49 $\mathrm{N}(0.11 \mathrm{lbf})$ load applied as discussed above. The mass remained unchanged for approximately 
15 minute while digital images were taken of the membrane. At the completion of a test case additional mass was added to the two corners and the sequence started again until the four load cases were completed. The desired loads and the actual loads applied to the corners are shown in Table 1.

\section{Instrumentation}

Photogrammetry was used to determine the surface profile within a pentagon shaped section that was approximately $250.0 \times 250.0 \times 212.5 \times 212.5 \times 53.0 \mathrm{~mm}$ in size with the apex located at the left corner of the membrane. The location of the measured area was shown in Fig 1. A symmetric pattern of spots was projected onto the non-aluminized side of the membrane using a standard slide projector and $35 \mathrm{~mm}$ slide. The projected spots were approximately $5.5 \mathrm{~mm}$ oncenter and $6.0 \mathrm{~mm}$ in diameter. To determine the spatial coordinates accurately the center of each target spot must be located in each image. This can be done automatically by the software provided that the spots are uniformly illuminated. Even the non-aluminized side of the membrane produced glare and non-uniform contrast across the membrane, therefore this side of the membrane was sprayed with a talc-based developer solution (Spotcheck SKD-S2 Developer, Magnaflux, Glenview, IL 60025). This type of developer is typically used to locate surface cracks in materials. The solution dried white and adhered but did not bond to the membrane surface. It could be wiped off easily. The coating provided a non-reflective surface to project targets onto the membrane. Two images were taken with identical, calibrated, digital cameras (Canon Powershot G1, Canon USA, Inc., Lake Success, NY, 11042) mounted approximately $610 \mathrm{~mm}$ from the membrane surface. The baseline between the two cameras was approximately $580 \mathrm{~mm}$. The cameras had a 2048 X 1536 pixel resolution. The images were processed using 
commercially available photogrammetry software (ShapeCapture, Shapequest Inc.). Photographs of the membrane with dot pattern are shown in Figs. 2(a)and 2(b).

A frame with control points surrounded the test area. The frame can be seen in Figs. 2(a) and 2(b). The frame was square with side lengths of $381 \mathrm{~mm}$ (15.0 in.) constructed from $25.4 \mathrm{~mm}$ wide by $6.25 \mathrm{~mm}$ thick ( $1.0 \mathrm{in}$. X $0.25 \mathrm{in}$.) Aluminum. Each side had three equally spaced control points. The control points were $12.5 \mathrm{~mm}(0.5 \mathrm{in}$.) in diameter, machined $0.254 \mathrm{~mm}(0.01$ in.) below the surface of the aluminum, and painted black. The control points were used to define the axes and determine image scale. This information was used within the software during the analysis and was also used to determine the accuracy of the measurements. Typical errors for $\mathrm{X}, \mathrm{Y}$, and $\mathrm{Z}$ measurements were approximately, $1.25 \times 10^{-3} \mathrm{~mm}, 1.25 \times 10^{-3} \mathrm{~mm}$, and $2.25 \mathrm{x}$ $10^{-3} \mathrm{~mm}$ respectively.

Although the images used for photogrammetry are of the non-aluminized side of the membrane the results presented are for the aluminized face of the membrane (i.e. facing the aluminized side of the membrane at the left corner). The phtogrammetry software outputs columns of $\mathrm{X}, \mathrm{Y}$, and $\mathrm{Z}$ data. For the section of membrane under study this was approximately 2000 data points. The data was put into matrix form using the Kriging method available within the Surfer Version 7 (Golden Software, Inc., Golden, CO 80401) plotting software. Once the data was in matrix form a smoothing operation was performed and the results plotted.

It is important to note that the amplitude data near the edge of the membrane may not always be reliable. Near the edges the radius of curvature of the membrane can be relatively small. This 
caused problems focusing the targets and presumably errors in the stereo matching between points. This type of error can result in incorrect determination of the amplitude value for the data point. Therefore, data points near the membrane edges that had $Z$ values significantly different from adjacent points were judiciously removed prior to processing the data.

\section{$\underline{\text { Experimental Results }}$}

The main goal of this investigation was to quantify the wrinkle pattern near the corner of a symmetrically loaded membrane. Experimental data was collected that determined the effect of loading on the number of wrinkles, wrinkle amplitude, and wrinkle angle. In this section results are presented for the four load cases in Table 1.

The first objective was to determine the number of wrinkles present for each load case. Figures 3-6 show isometric and contour plots for each case. Cases 1 and 2 have two wrinkles, while cases 3 and 4 show four distinct wrinkles. Along with the wrinkling, cases 1 and 2 show a slack region near the $\mathrm{Y}$-axis. For case 1 the slack region begins at approximately $150 \mathrm{~mm}$. For case 2 the region is somewhat smaller. The slack region disappears as the loads are increased as is the shown in cases 3 and 4 . Clearly, as the loads increased the number of wrinkles increased.

The wrinkle angle was determined by measuring the direction of each wrinkle with respect to the $\mathrm{X}$-axis. This was done using the contour plots. Lines were drawn on the contour plots as shown in Fig. 7. Valleys are denoted by a V, while peaks are denoted by a P. The angle measurements for all load cases appear in Table 2. 
To measure the wrinkle amplitude the displacement data along diagonals from $Y=80 \mathrm{~mm}$ to $X=80 \mathrm{~mm}, Y=100 \mathrm{~mm}$ to $X=100 \mathrm{~mm}$, and $Y=150$ to $X=150 \mathrm{~mm}$ were plotted in Fig. 8-11(a)-(c).

Data along the diagonal was used because it was approximately perpendicular to the wrinkles. Wrinkle amplitude was determined by measuring the difference between the valley near the center of the diagonal to the two nearest peaks. The figures show that, in general, the wrinkle amplitude decreases with increasing load. Figure $8(\mathrm{~b})$ and (c) show that for the case 1 the wrinkle amplitude is approximately $0.5 \mathrm{~mm}$ while for case 4 it is $0.25 \mathrm{~mm}$.

\section{Analysis of Experiments}

An analysis of the laboratory experiments was performed to predict the wrinkling behavior of the membrane. The following sections present the technique used to analyze the wrinkled membrane, the details of the finite element model, and a summary of the results including a comparison between analytical predictions and experimental results.

\section{Analysis Technique}

Nonlinear analysis techniques are required in order to accurately account for geometric nonlinearities, load stiffening, and wrinkling effects in the analysis of membrane structures. The analysis technique used to predict the wrinkled membrane response in this study is a finite element implementation of Stein-Hedgepeth wrinkling theory. ${ }^{1,15}$ According to Stein-Hedgepeth theory the stress state in a wrinkled region of a membrane is uni-axial (positive major principal stress and zero minor principal stress) and wrinkles form in straight lines along the direction of the major principal stresses (load transfer in the wrinkled region is along these lines). The theory predicts average strains and displacements, not individual wrinkle details, in the wrinkled region. 
The analysis is performed using the commercially available finite element analysis program $\mathrm{ABAQUS}^{16}$ with membrane wrinkling effects accounted for through the use of a user defined material (UMAT) subroutine developed by Adler. ${ }^{17}$ The analysis procedure is as follows. First, a finite element model of the structure is generated and membrane elements are assigned the wrinkling material model. Next, a nonlinear static analysis of the structure performed during which the state of each element integration point is determined using a wrinkling criteria $\left(\sigma_{2}>0\right.$

$\rightarrow$ taut, $\varepsilon_{1} \leq 0 \rightarrow$ slack, $\varepsilon_{1}>0$ and $\sigma_{2} \leq 0 \rightarrow$ wrinkled) and the stiffness matrix for slack and wrinkled elements is modified accordingly.

\section{Finite Element Model}

The finite element model of the laboratory experiment is shown in Fig. 9. The model includes the membrane, corner reinforcements, and Kevlar threads. The membrane is modeled using 39976 membrane elements (ABAQUS M3D4 and M3D3 elements) which are assigned the wrinkling material model. The corners are modeled with 64 shell elements (ABAQUS S3 elements), and the threads are represented using 20 beam elements (ABAQUS B31 elements). A summary of material properties used in the analysis is presented in Table 3 . The point loads are applied at the ends of the right and bottom Kevlar threads. The boundary conditions are applied at the ends of the Kevlar threads attached to the test fixture. The ends of the top and left threads are constrained in all three translational degrees of freedom, while the right and bottom threads are constrained in the two translational degrees of freedom normal to the loading direction. 


\section{Analytical Results}

The structural response of the membrane was analyzed for each of the four load cases investigated in the laboratory experiments. Table 4 presents a summary of the maximum stress and the stress at the center of the membrane for each of the load cases. The stress levels are consistent with those of future gossamer spacecraft applications such as the NGST sunshield. ${ }^{5}$

Plots of the major and minor principal stress distributions in the membrane are given in Fig. 10. The plot of the major principal stresses shows that there are stress concentrations at the corners of the membrane where the loads are applied, however the central region of the membrane has a relatively uniform stress distribution. The minor principal stress plot reveals that there is a region of near-zero minor principal stress around the corners and outside edges of the membrane. Recall from Stein-Hedgepeth theory that the minor principal stresses are zero in wrinkled regions of the membrane. Figure 11 presents plots of the predicted wrinkle region in the membrane for load case $3(2.45 \mathrm{~N}$ corner load). These plots were generated by outputting the element integration point states during the course of the analysis. The completely wrinkled region, Fig. 11(a), consists of elements for which all integration points have a wrinkled state, while the partially wrinkled region, Fig. 11(b), encompasses elements for which at least one integration point has a wrinkled state. Fig. 11(c) shows the total wrinkled region consisting of both completely and partially wrinkled elements. The wrinkle region is seen to extend from the corners around the edges of the membrane. Note that a comparison of the size and shape of the wrinkle region for each of the four load cases shows that the magnitude of the corner loads has an insignificant effect on the characteristics (shape and size) of the wrinkle region. 


\section{Comparison of Analysis and Experiment}

Predictions from the finite element analysis were compared with results from the laboratory experiments. Since the analysis technique is not capable of predicting the details of the membrane wrinkling, comparisons are made for the extent of the wrinkle region and the direction of the wrinkles. Figure 12 provides a comparison of the predicted and measured wrinkle regions. The general shape of the wrinkle zone is seen to be similar, although the analysis predicts a smaller wrinkle region than is measured in the laboratory. The extent of the predicted wrinkle region extends approximately $43 \%$ of the distance from the corner to the center of the membrane, while the measured region extends approximately $59 \%$ of this distance. The comparison is somewhat complicated in that there is not a well-defined boundary to the wrinkle zone in the experimental data.

Figure 13 presents a comparison of the predicted major principal stress directions and the measured wrinkle angles (for both the troughs and crests of the wrinkles) in the right-hand corner of the membrane. Both the angular measurements are taken from the $\mathrm{x}$-axis as defined in Fig. 7 . Recall that Stein-Hedgepeth theory predicts that wrinkles form in straight lines along the direction of the major principal stresses, thus the measured wrinkle angles are expected to fall along the predicted major principal stress angles. Good agreement between the predicted and measured results is seen in the central region, while the results show less favorable agreement towards the edges of the membrane. This is explained to a certain degree by the less welldefined nature of the wrinkles near the edges of the membrane in the experimental data. Additionally, the wrinkles near the edges are close to the boundary of the wrinkle zone and their behavior may not follow theory as well as those in the center of the wrinkle zone. 


\section{Concluding Remarks}

A combined experimental and computational investigation of corner wrinkling of a square Kapton membrane was presented. The membrane was subjected to symmetric corner loads that ranged from $0.49-4.9 \mathrm{~N}$. The wrinkling behavior of the membrane was characterized in the laboratory using photogrammetry. The experimental results showed that as the loads increased the number of wrinkles increased, but the amplitude decreased. An analysis of the experiments was performed using a computational technique that accounts for membrane wrinkling effects. Relevant results from the analytical model include predictions for the extent of the wrinkled region and the directions of the wrinkles. The experiments showed that the wrinkled region was somewhat larger than that predicted by the model. Theory predicts that wrinkles will form along straight lines in the direction of the major principle stresses. The computational results show reasonably good agreement between the wrinkle angle with respect to the $\mathrm{X}$-axis and the direction of the major principle stresses.

Although the focus of this paper has been symmetric mechanical loading, preliminary work into the effect of heating has shown that thermal effects may have a significant effect on the membrane wrinkle pattern. This will be the focus of a future paper.

\section{$\underline{\text { References }}$}

1. Stein, M. and Hedgepeth, J.M., “Analysis of Partly Wrinkled Membranes”. NASA TN D$813,1961$.

2. Gorman, D.J. and Singhal, R.K., "A Superposition-Ryleigh-Ritz Method for Free Vibration Analysis of Non-Uniformly Tensioned Membranes". Journal of Sound and Vibration, Vol. 162, No. 3, 1993, pp. 489-501. 
3. Jenkins, C.H. and Leonard, J.W., "Nonlinear Dynamic Response of Membranes: State of the Art," Applied Mechanics Reviews, American Society of Mechanical Engineers, Vol. 44, No. 7, July 1991, pp. 319-328.

4. Lienard, S.L., "Characterization of Large Thin Film Membrane Dynamic Behavior with UAI-NASTRAN Finite Element Solver,” SAE Paper 199-01-5518, October 1999.

5. Johnston, J. and Lienard, S., "Modeling and Analysis of Structural Dynamics for a OneTenth Scale Model NGST Sunshield", Proceedings of the 42 nd AIAA/ASME/ASCE,/AHS/ASC Structures, Structural Dynamics, and Materials Conference, Seattle, WA, April 16-19, 2001, AIAA-2001-1407.

6. Adler, A.L., Mikulas, M.M., and Hedgepeth, J.M., "Static and Dynamic Analysis of Partially Wrinkled Membrane Structures," Proceedings of the 41 st AIAA Structures, Structural Dynamics, and Materials Conference, Atlanta, GA, Paper No. AIAA-2000-1810, April 2000.

7. Xinxiang, L., Jenkins, C., and Schur, W., "Fine Scale Analysis of Wrinkled Membranes," to appear in International Journal of Computational Engineering and Science, 2000.

8. Sewall, J. L., Miserentino, R., and Pappa, R. S., "Vibration Studies of a Lightweight ThreeSided Membrane Suitable for Space Application," NASA TP-2095, January 1983.

9. Thomas, M. and Veal, G., "Highly Accurate Inflatable Reflectors," AFRPL Report TR-84$021,1984$.

10. Jenkins, C.H., Haugen, F., and Spicher, W.H., "Experimental Measurement of Wrinkling in Membranes Undergoing Planar Deformation," Experimental Mechanics, Vol. 38, No. 2, June 1998, pp. 147-152.

11. Wong, Y.W., "Analysis of Wrinkle Patterns in Prestressed Membrane Structures," Master's Thesis, University of Cambridge, Department of Engineering, August 2000.

12. Kukathasan, S., "Vibration of Prestressed Membrane Structures," Master's Thesis, University of Cambridge, Department of Engineering, August 2000.

13. Pappa, R.S., Giersch, L.R. and Quagliaroli, J.M.,"Photogrammetry of a $5 \mathrm{~m}$ Inflatable Space Antenna with Consumer Digital Cameras," Pre publication manuscript, 2000.

14. Blandino, J.R., Johnston, J.D., Miles, J.J., Soplop, J.S., "Thin Film Membrane Wrinkling due to Mechanical and Thermal Loads," Proceedings of the $42^{\text {nd }}$ AIAA/ASME/ASCE/AHS/ASC Structures, Structural Dynamics, and Materials Conference, Seattle, WA, 16-19 April, 2001, AIAA-2001-1345.

15. Miller, R.K. and Hedgepeth, J.M., "An Algorithm for Finite Element Analysis of Partly Wrinkled Membrane Structures," AlAA Journal, Vol. 20, No. 12, December 1982, pp. 1761 1763. 
16. Adler, A.L., "Finite Element Approaches for Static and Dynamic Analysis of Partially Wrinkled Membrane Structures," PhD Thesis, Department of Aerospace Engineering, University of Colorado, Boulder, CO, 2000.

17. ABAQUS /Standard User's Manual, Version 6.1, Hibbitt, Karlsson, \& Sorensen, Inc., Pawtucket, RI, 2000. 
Table 1: Summary of applied loads.

\begin{tabular}{|l|c|c|c|}
\hline & \multirow{2}{*}{ Desired } & \multicolumn{2}{|c|}{ Actual Loads } \\
\cline { 4 - 4 } & Load & Side & Bottom \\
\hline Case 1 & $0.491 \mathrm{~N}$ & $0.490 \mathrm{~N}$ & $0.483 \mathrm{~N}$ \\
\hline Case 2 & $1.471 \mathrm{~N}$ & $1.470 \mathrm{~N}$ & $1.462 \mathrm{~N}$ \\
\hline Case 3 & $2.452 \mathrm{~N}$ & $2.450 \mathrm{~N}$ & $2.442 \mathrm{~N}$ \\
\hline Case 4 & $4.905 \mathrm{~N}$ & $4.898 \mathrm{~N}$ & $4.891 \mathrm{~N}$ \\
\hline
\end{tabular}


Table 2. Wrinkle angle measured from X-axis.

\begin{tabular}{|l|l|l|l|l|}
\hline & $\mathbf{0 . 4 9 N}$ & $\mathbf{1 . 4 7 N}$ & $2.45 \mathrm{~N}$ & $4.9 \mathrm{~N}$ \\
\hline Valley 1 & $62.48^{\circ}$ & $72.26^{\circ}$ & $76.49^{\circ}$ & $80.40^{\circ}$ \\
\hline Peak 1 & $58.88^{\circ}$ & $62.32^{\circ}$ & $71.95^{\circ}$ & $73.52^{\circ}$ \\
\hline Valley 2 & $45.13^{\circ}$ & $49.05^{\circ}$ & $68.08^{\circ}$ & $65.99^{\circ}$ \\
\hline Peak 2 & $36.21^{\circ}$ & $35.04^{\circ}$ & $62.24^{\circ}$ & $58.97^{\circ}$ \\
\hline Valley 3 & $10.75^{\circ}$ & $8.51^{\circ}$ & $46.19^{\circ}$ & $47.15^{\circ}$ \\
\hline Peak 3 & & & $37.63^{\circ}$ & $39.57^{\circ}$ \\
\hline Valley 4 & & & $27.49^{\circ}$ & $33.40^{\circ}$ \\
\hline Peak 4 & & & $25.70^{\circ}$ & $25.74^{\circ}$ \\
\hline Valley 5 & & & $9.69^{\circ}$ & $11.74^{\circ}$ \\
\hline
\end{tabular}


Table 3: Summary of material properties.

\begin{tabular}{|c|c|c|c|}
\hline Component & Material & $\mathbf{E}\left(\mathbf{N} / \mathbf{m}^{2}\right)$ & $v$ \\
\hline Membrane & Kapton $\mathrm{HN}$ & $2.5 \mathrm{E}+9$ & 0.34 \\
\hline Corner reinforcement & Mylar & $3.8 \mathrm{E}+9$ & 0.3 \\
\hline Thread & Kevlar & $7.05 \mathrm{E}+10$ & 0.36 \\
\hline
\end{tabular}


Table 4: Summary of predicted membrane stresses.

\begin{tabular}{|l|l|l|}
\hline Load Case & $\begin{array}{l}\sigma_{\text {maximum }} \\
\mathbf{N} / \mathbf{m}^{2}(\mathbf{p s i})\end{array}$ & $\begin{array}{l}\sigma_{\text {center }} \\
\mathbf{N} / \mathbf{m}^{2}\end{array}$ \\
\hline 1 & $1.49 \mathrm{Esi}+6(216)$ & $4.26 \mathrm{E}+4(6)$ \\
\hline 2 & $4.49 \mathrm{E}+6(651)$ & $1.28 \mathrm{E}+5(19)$ \\
\hline 3 & $7.50 \mathrm{E}+6(1087)$ & $2.13 \mathrm{E}+5(31)$ \\
\hline 4 & $1.51 \mathrm{E}+7(2186)$ & $4.25 \mathrm{E}+5(62)$ \\
\hline
\end{tabular}




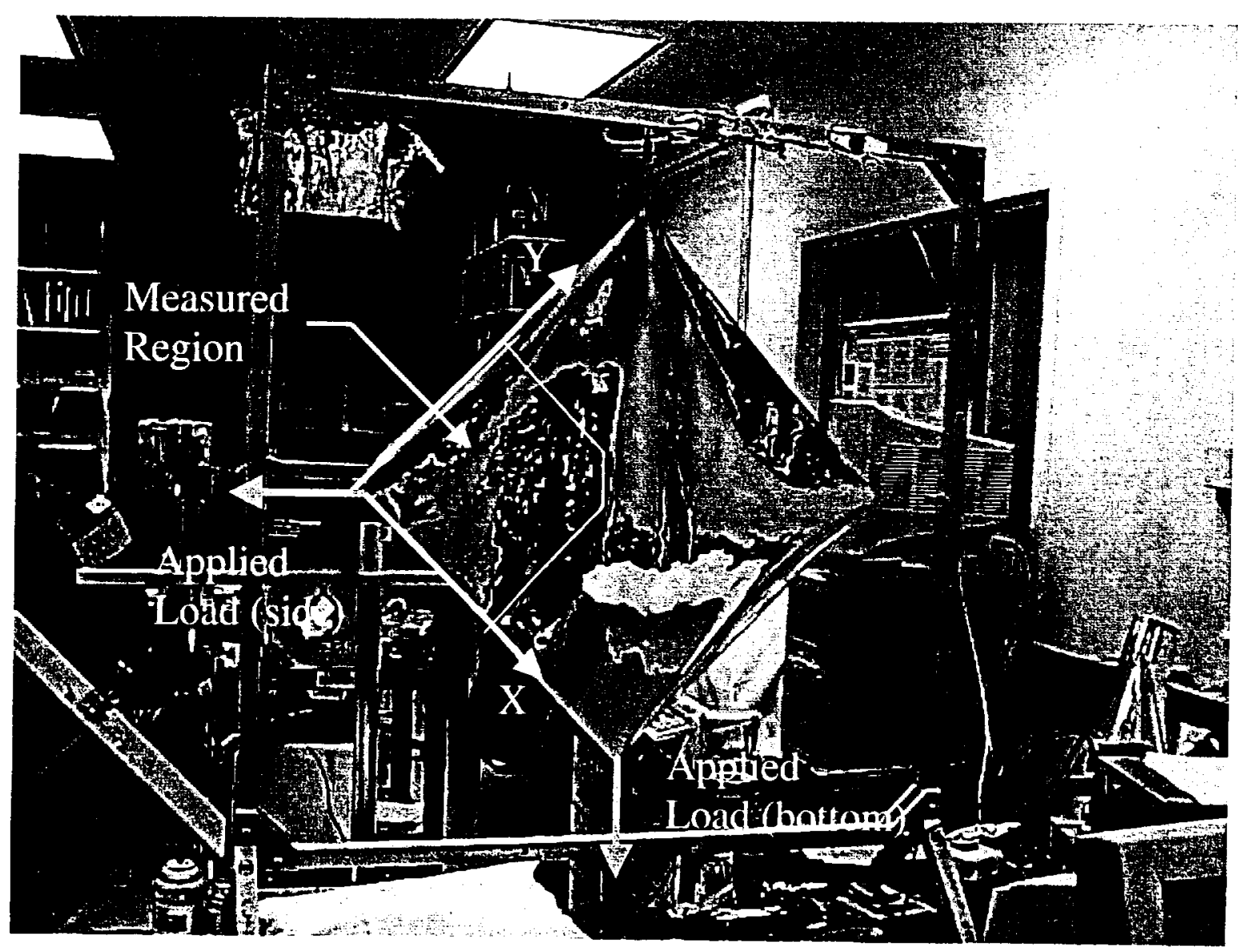

Figure 1. Membrane mounted in test frame. Axes, direction of applied loads, and measured region are shown. 


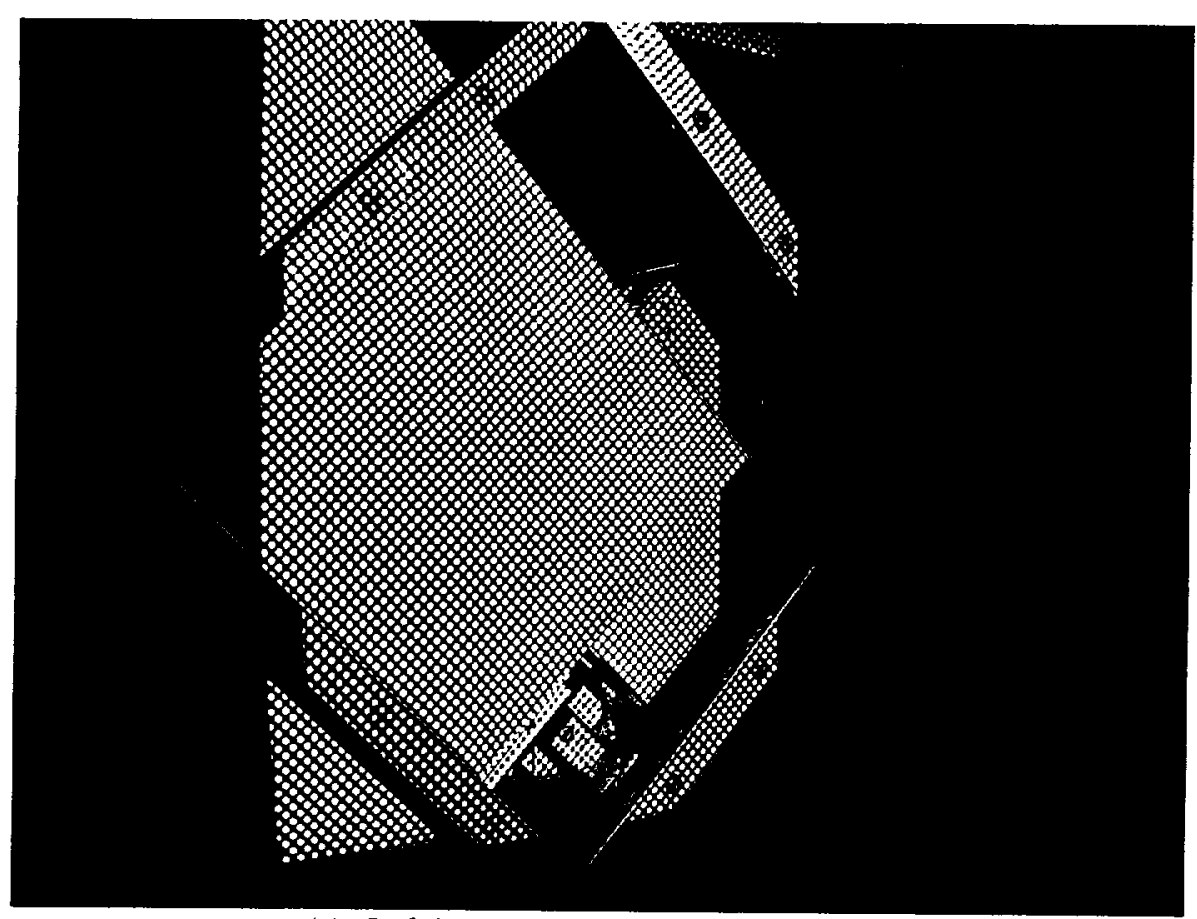

(a) Left image used for photogrammetry.

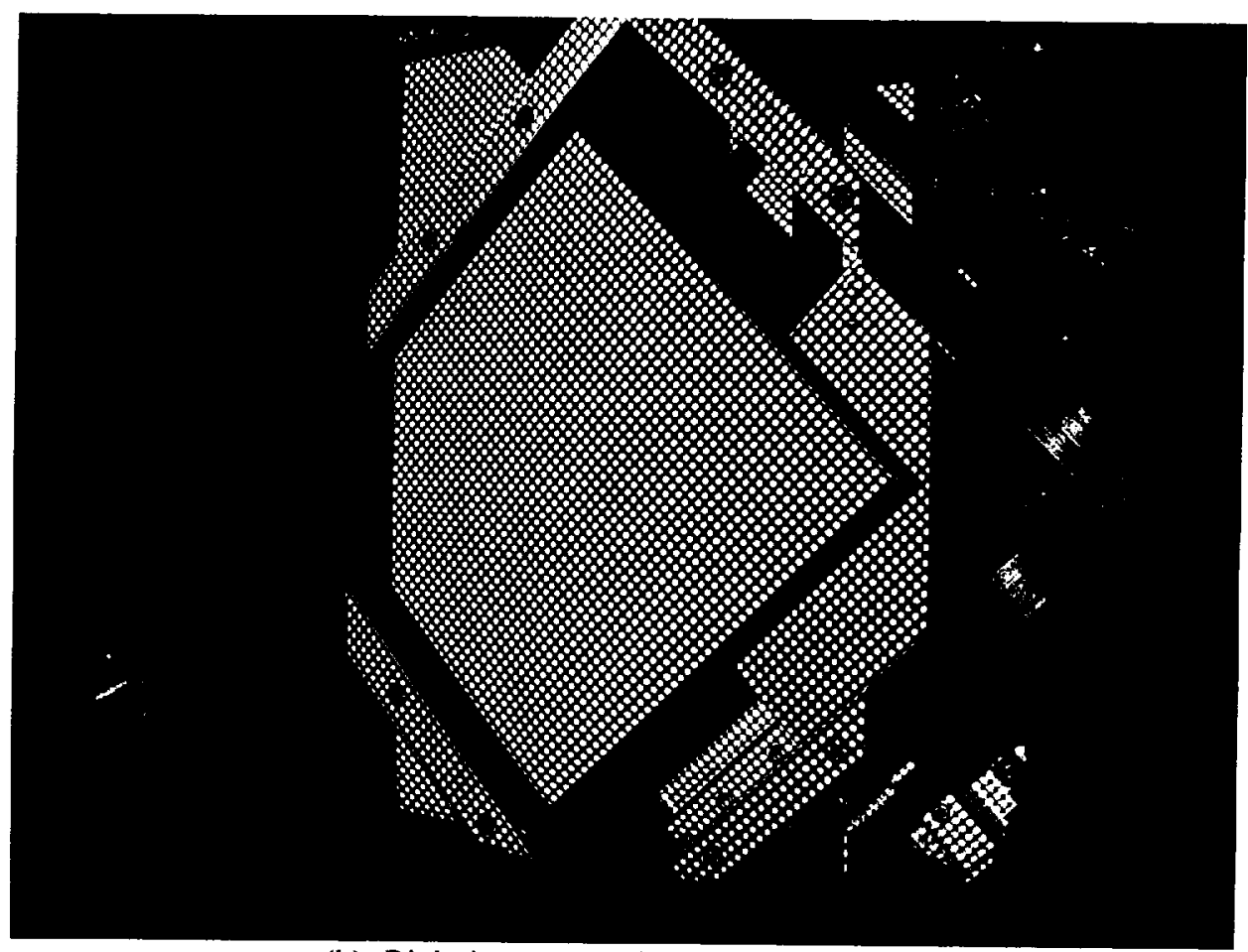

(b) Right image used for photogrammetry.

Figure 2. Typical images used for photogrammetry. Frame with control points can also be seen 


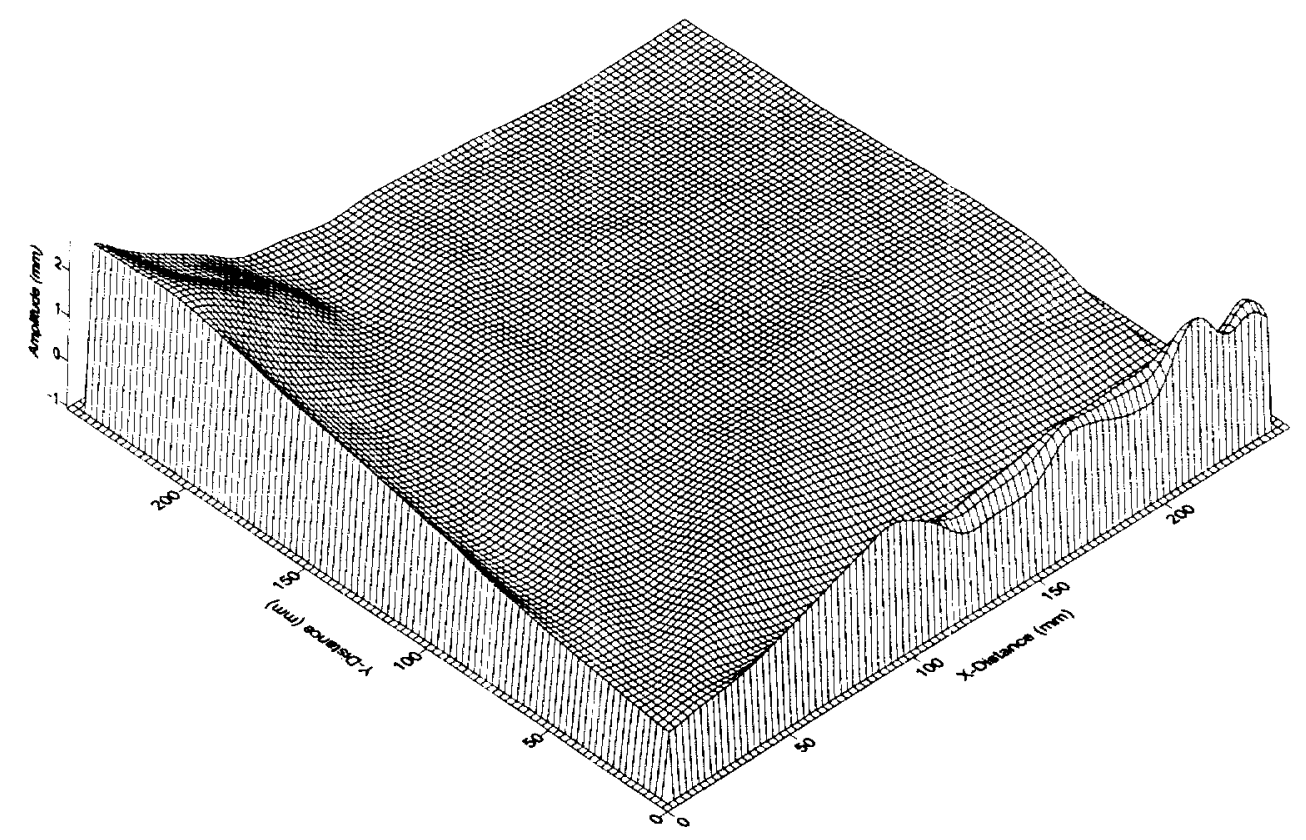

(a) Isometric view of corner section

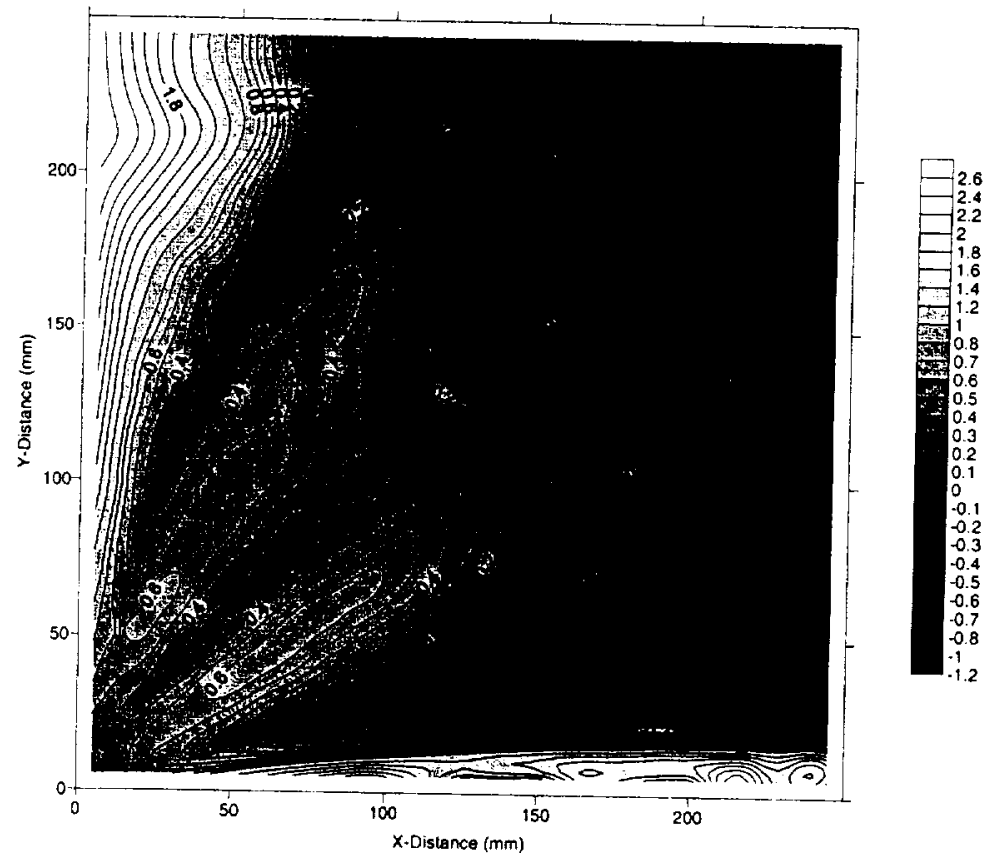

(b) Contour plot of corner section

Figure 3. Isometric and contour plots of corner section of membrane subjected to $0.491 \mathrm{~N}$ loads 


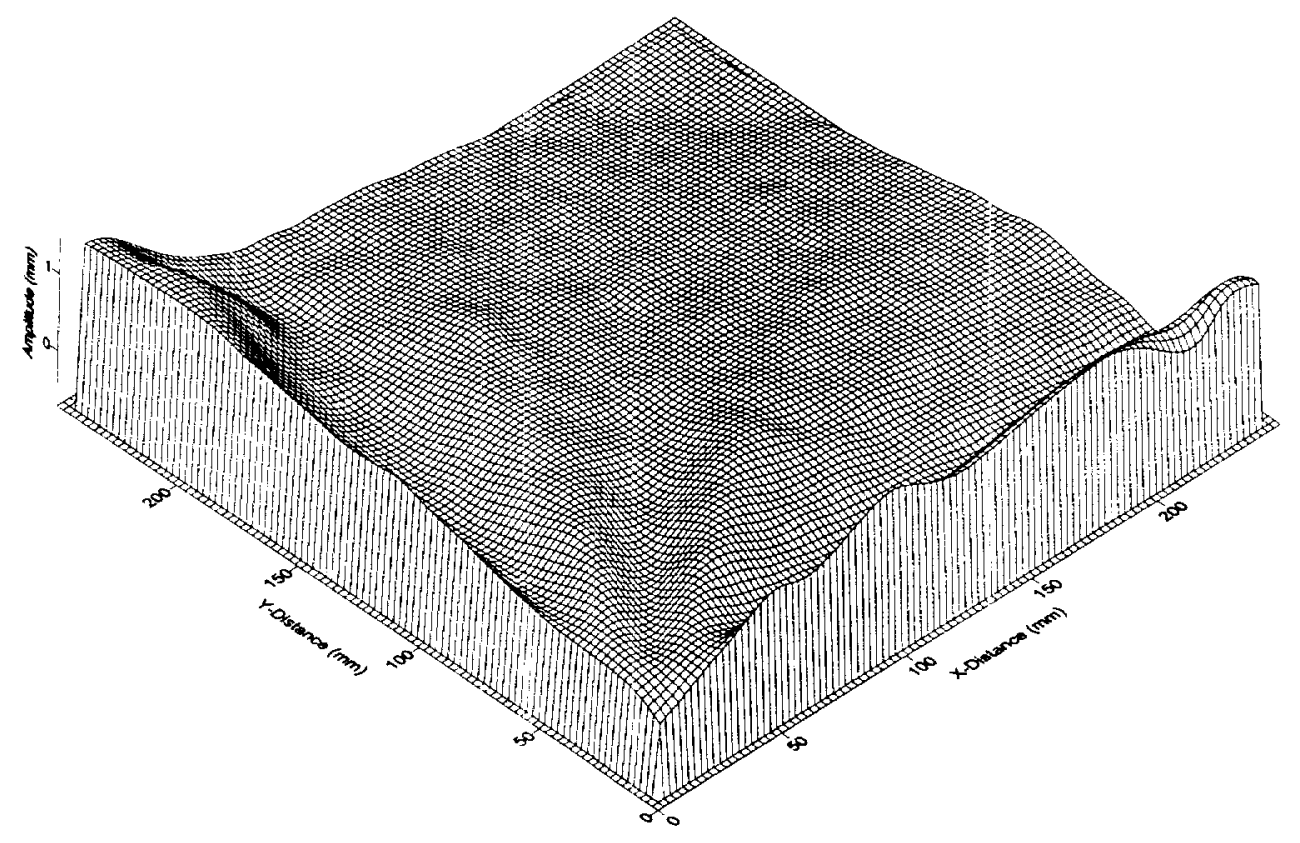

(a) Isometric view.

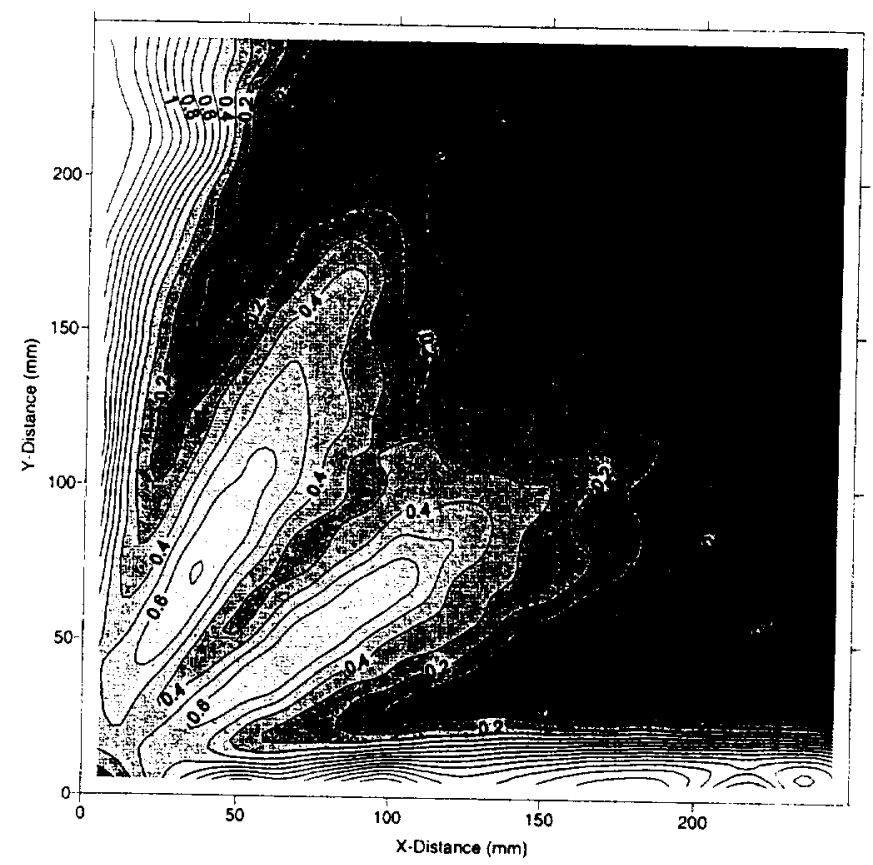

(b) Contour plot.

Figure 4. Isometric and contour plots of corner section of membrane subjected to $1.471 \mathrm{~N}$ loads 


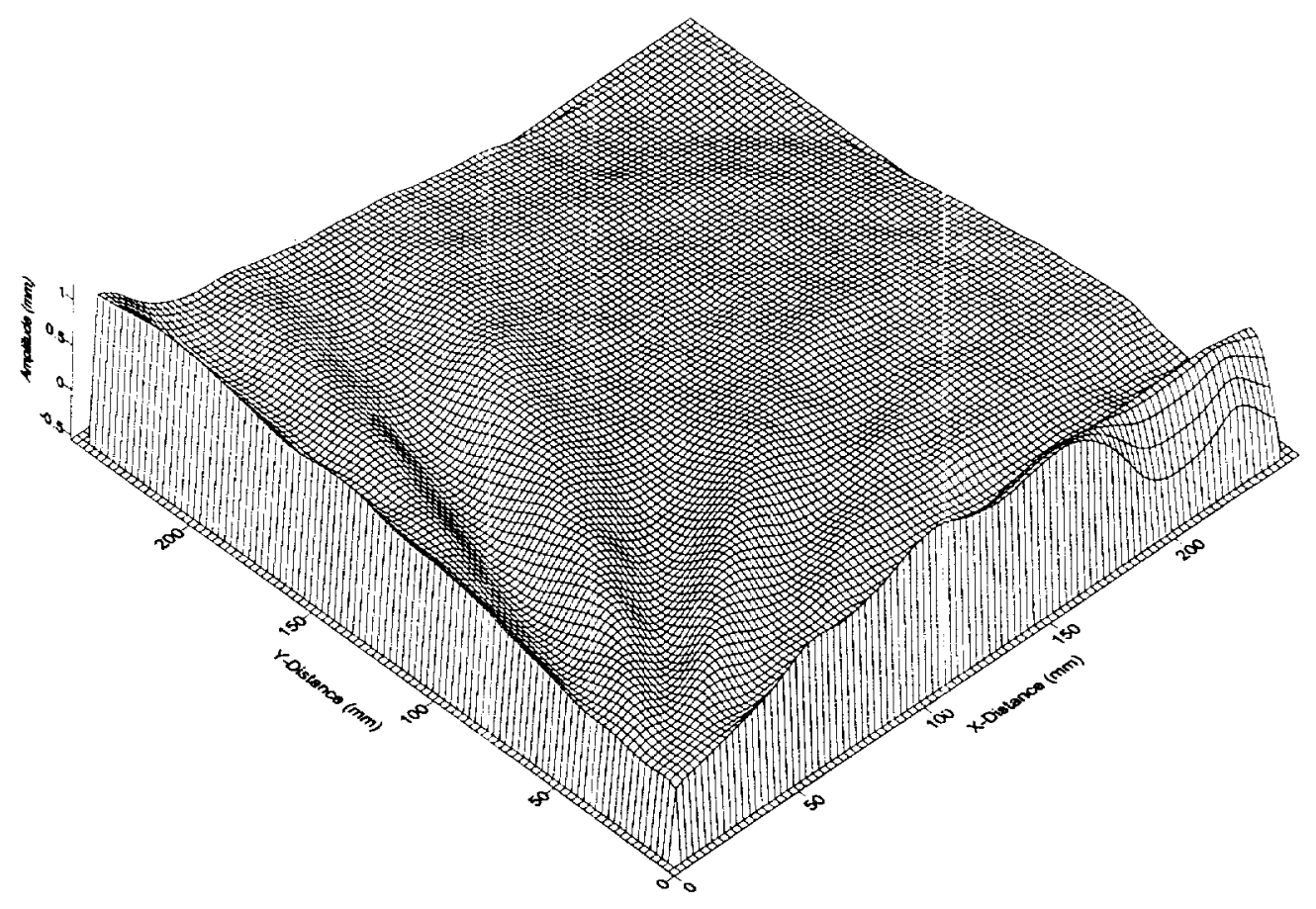

(a) Isometric view.

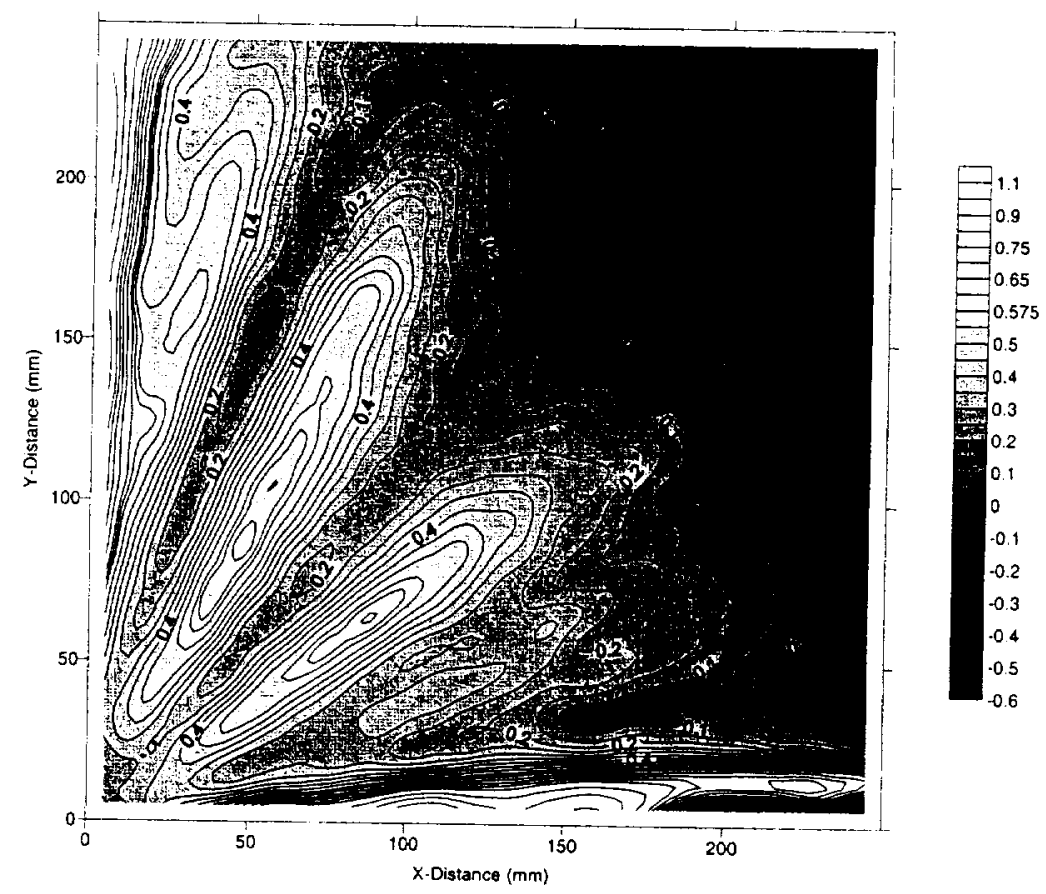

(b) Contour plot.

Figure 5. Isometric and contour plots of corner section of membrane subjected to $2.452 \mathrm{~N}$ loads 


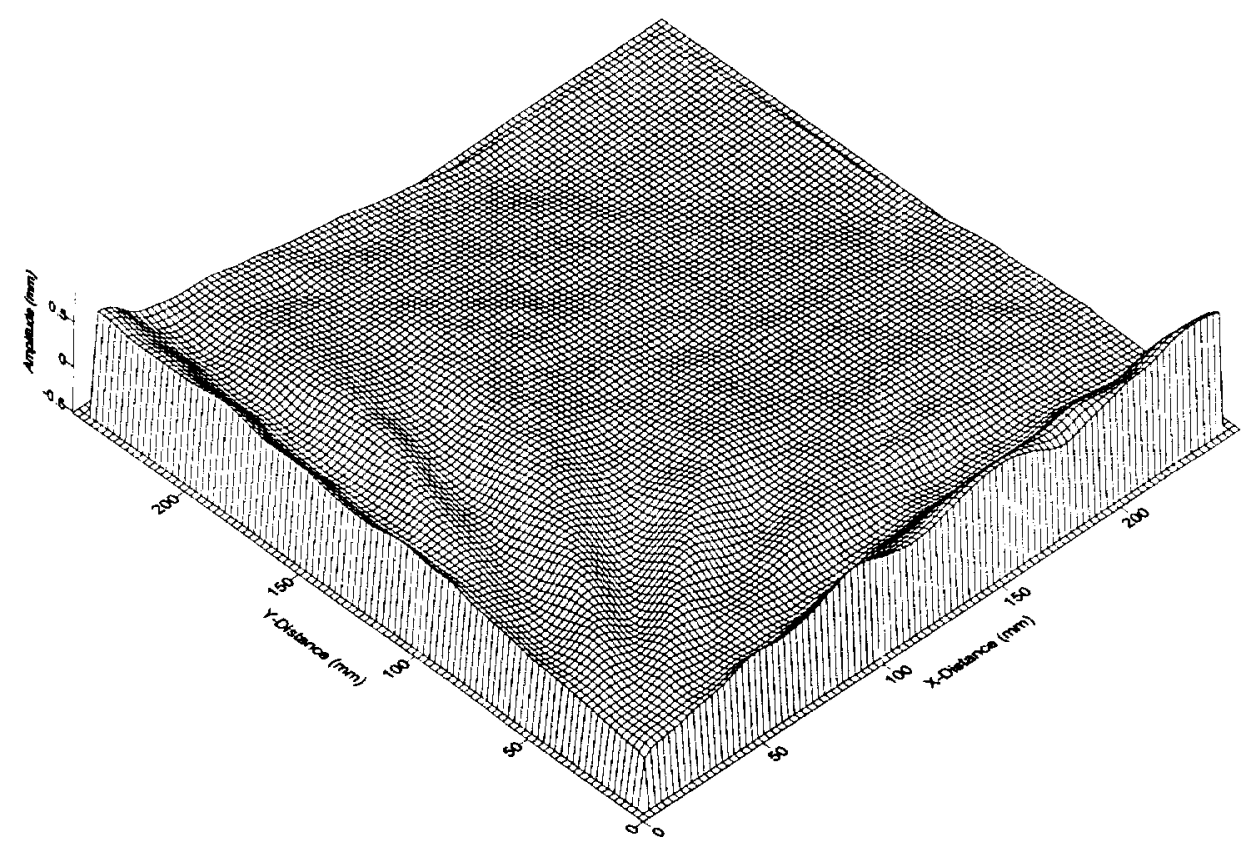

(a) Isometric view

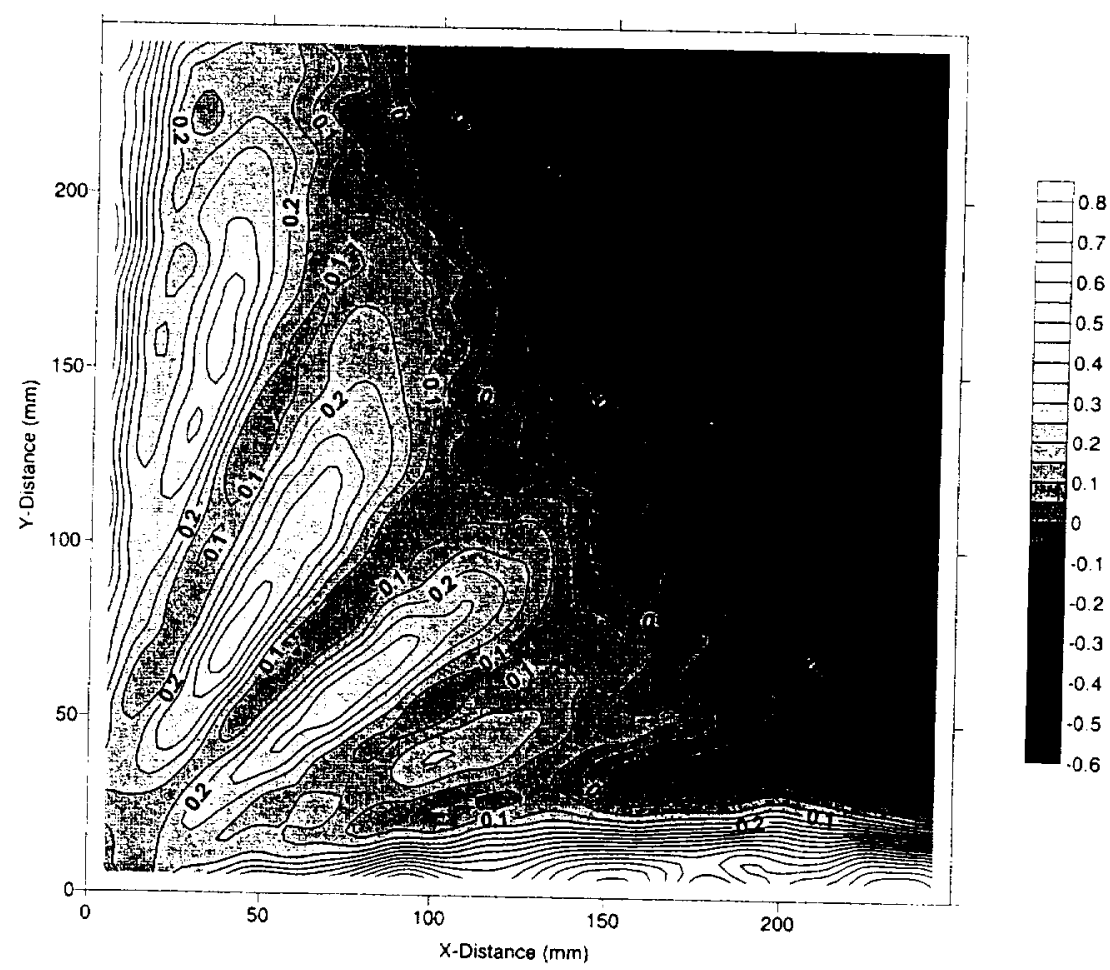

(b) Contour plot.

Figure 6. Isometric and contour plots of corner section of membrane subjected to $4.905 \mathrm{~N}$ loads. 


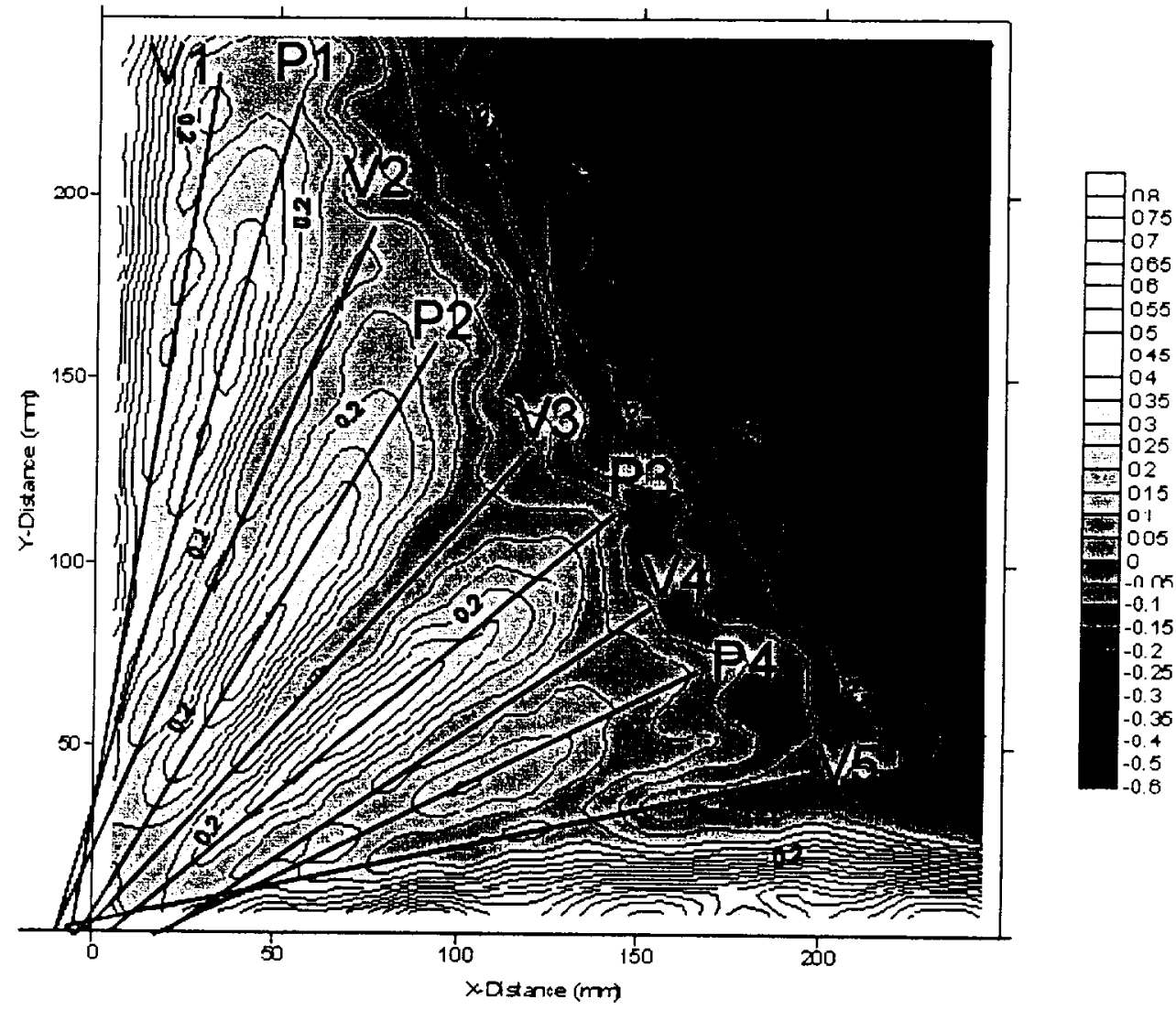

Figure 7. Typical contour plot showing location of Valleys and Peaks with respect to the $\mathrm{X}$-axis. 


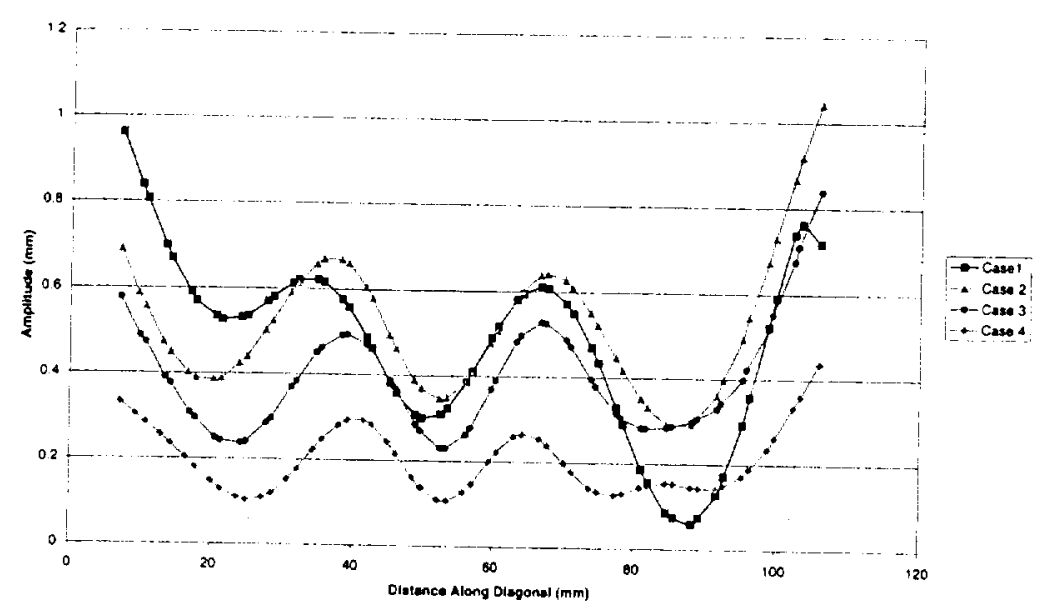

(a) $Y=80 \mathrm{~mm}$ to $X=80 \mathrm{~mm}$

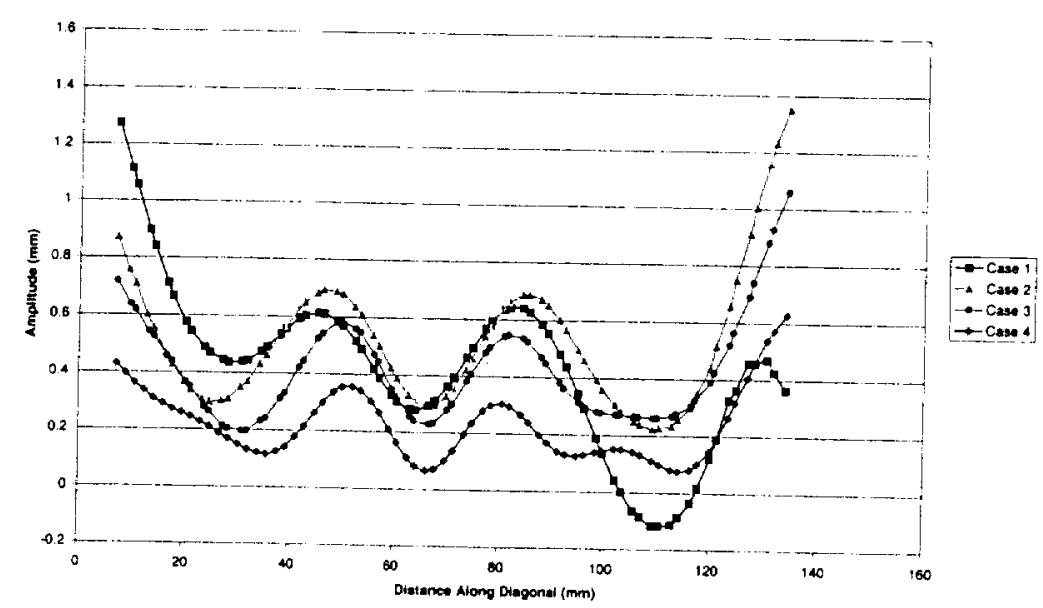

(b) $Y=100 \mathrm{~mm}$ to $X=100 \mathrm{~mm}$

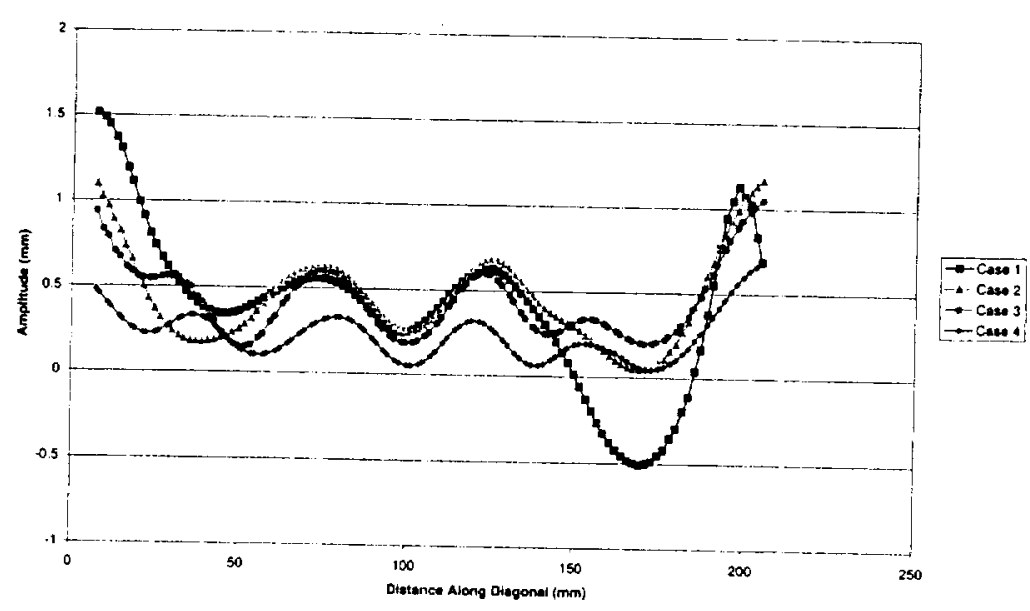

(c) $Y=150 \mathrm{~mm}$ to $X=150 \mathrm{~mm}$

Figure 8. Amplitude data along a diagonal line from $Y=80 \mathrm{~mm}$ to $X=80 \mathrm{~mm}, Y=100 \mathrm{~mm}$ to $X=100 \mathrm{~mm}$, and $Y=150 \mathrm{~mm}$ to $X=150 \mathrm{~mm}$ 


\section{P DOF 123 $=0$}

DOF $123=0$

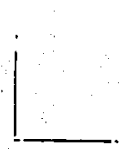

$\mathrm{P}=2.45 \mathrm{~N}$ DOF $23=0$ $\triangle$

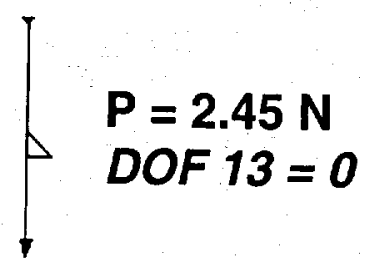

Figure 9: Finite element model of membrane experiment. 


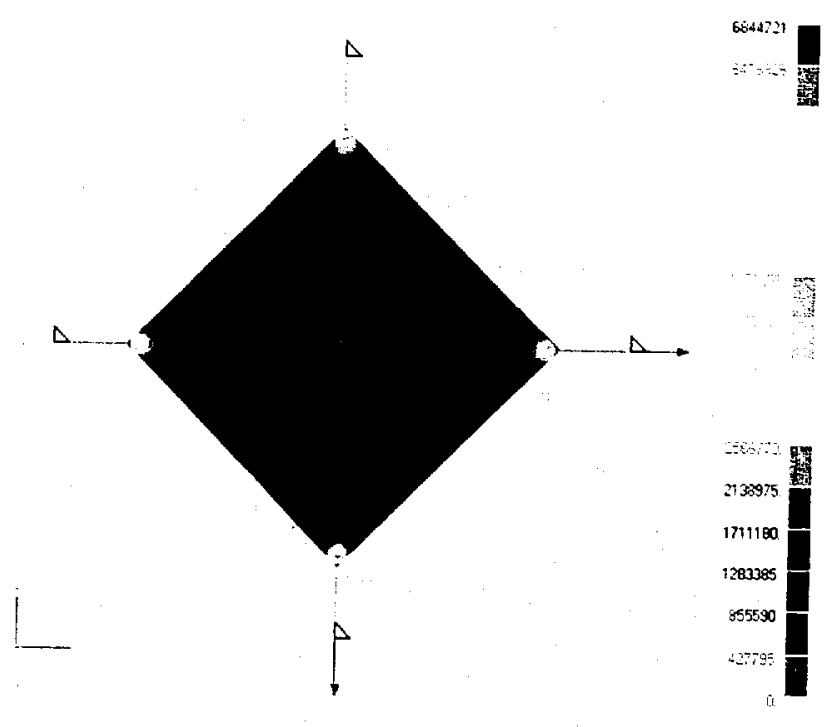

(a) Major principal stresses

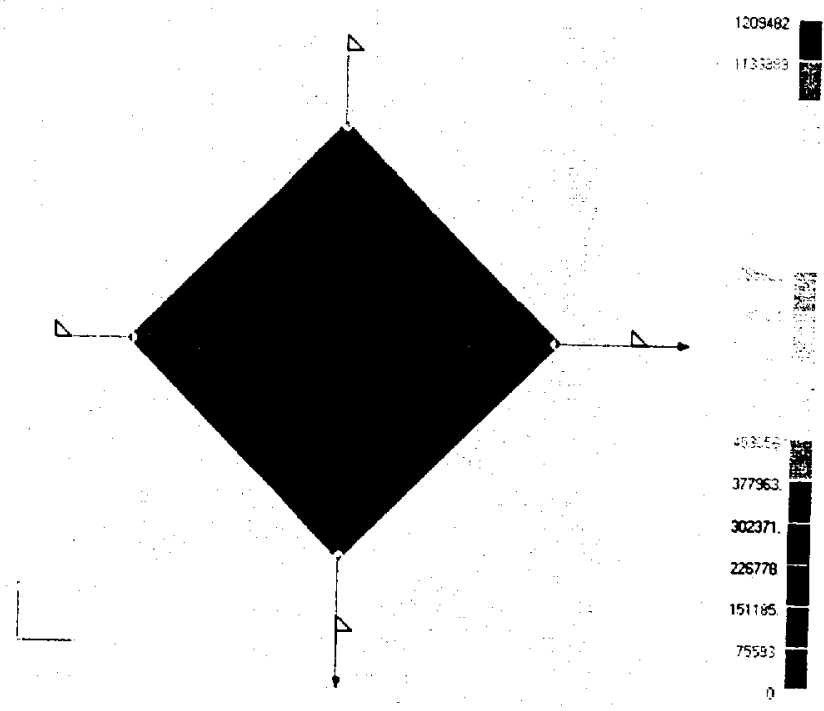

(b) Minor principal stresses

Figure 10: Principal stresses in membrane predicted by finite element analysis for the case 3 , a $2.45 \mathrm{~N}$ corner load. 
Figure 11: Predicted wrinkle regions in membrane: (a) completely wrinkled elements, (b) partially wrinkled elements, and (c) all wrinkled elements. 


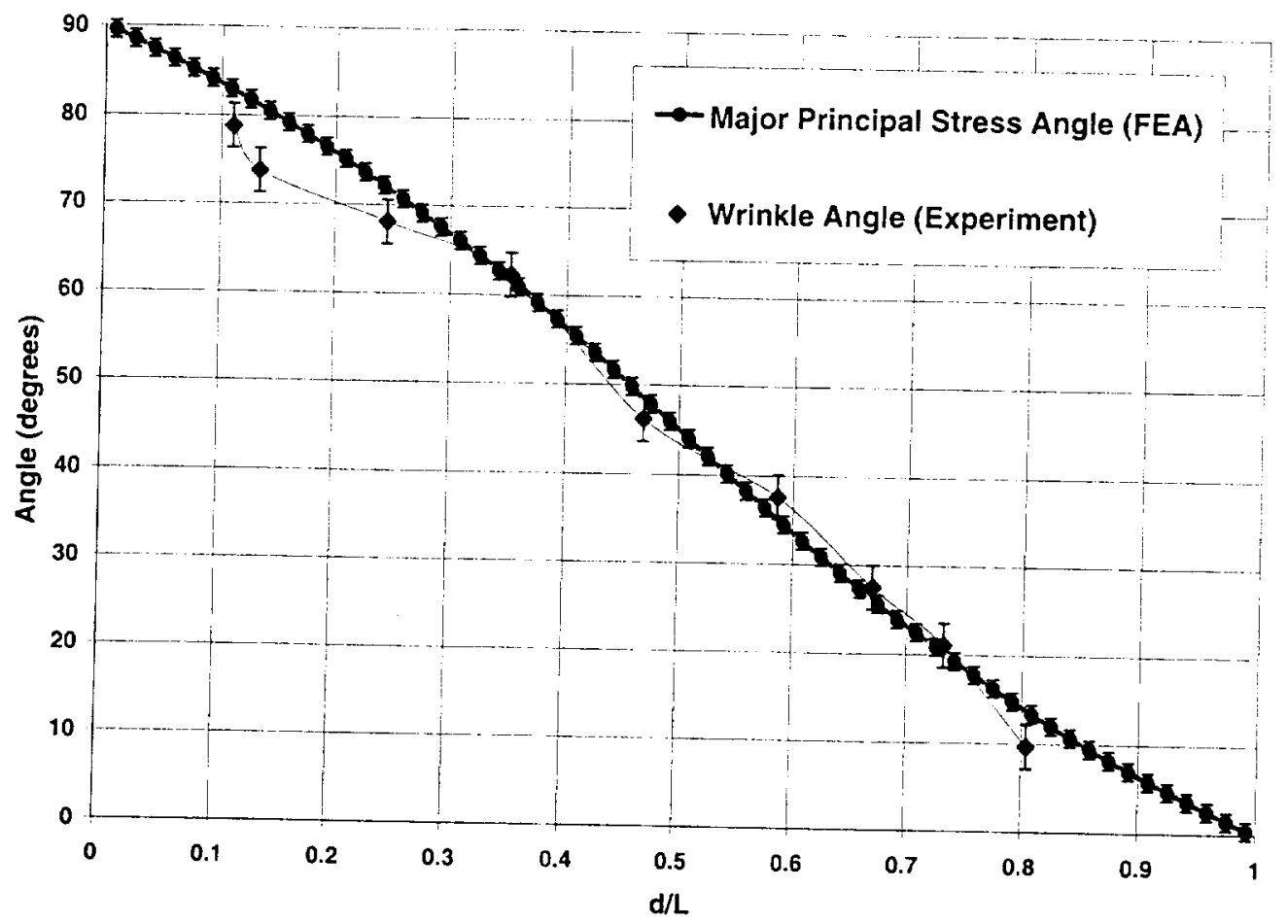

Figure 13: Comparison of predicted major principal stress directions and measured wrinkle angles in left-hand corner of membrane. 